\title{
CARACTERIZACIÓN DEL POTENCIAL TURÍSTICO DEL GEOPARQUE VILLUERCAS-IBORES-JARA (EXTREMADURA, ESPAÑA)
}

\author{
David Lagar Timón \\ Diputación Provincial de Cáceres \\ dlagar@dip-caceres.es \\ Ramón García Marín \\ Universidad de Murcia \\ ramongm@um.es \\ Manuel Pulido Fernández \\ Universidad de Extremadura \\ mapulidof@unex.es
}

\section{Resumen}

En el marco de las tendencias sobre valorización de recursos naturales por la actividad turística, se presenta un estudio de caso referido a la comarca de Villuercas-Ibores-Jara (Comunidad Autónoma de Extremadura, España). El territorio objeto de estudio posee unos recursos geológicos, naturales y culturales que necesitan ser potenciados y gestionados por su valor patrimonial. En este trabajo se analizan los 15 geositios considerados de mayor potencial para el turismo y se documentaron mediante unas fichas que recogen aspectos como la situación geográfica, el estado de conservación, cualidades o su importancia geológica. Entre ellos pueden ser destacados la Cueva del Castañar de Ibor, el Sinclinal de Santa Lucía o el Nacimiento del Río Almonte. Sobre la base de dichos recursos, se analiza el modelo de gestión del patrimonio geológico y geomorfológico del recién declarado Geoparque Villuercas-Ibores-Jara que tiene como puntos fuertes la conservación, la revalorización, el estudio y la difusión del patrimonio geológico en el marco de un turismo de naturaleza y sostenible.

PALABRAS CLAVE: Villuercas-Ibores-Jara, Geoparque, Patrimonio geológico, Turismo sostenible, Geositios 


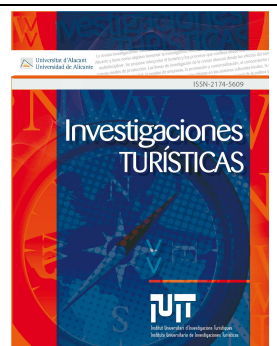

\title{
ANALYSIS OF TOURISM POTENTIAL IN THE GEOPARK VILLUERCAS- IBORES-JARA (EXTREMADURA, SPAIN)
}

\author{
David Lagar Timón \\ Diputación Provincial de Cáceres \\ dlagar@dip-caceres.es \\ Ramón García Marín \\ Universidad de Murcia \\ ramongm@um.es \\ Manuel Pulido Fernández \\ Universidad de Extremadura \\ mapulidof@unex.es
}

\begin{abstract}
Villuercas-Ibores-Jara region (Extremadura, Spain) has some geological, natural and cultural resources that should be empowered and correctly managed due to their heritage value. In this paper the most important for tourism 15 geosites were analyzed and well documented in information sheets concerning to their geographical location, conservation state, potentialities and geological importance. Among them Cave of Castañar de Ibor, the Syncline of St. Lucía and the Source of Almonte River may be highlighted. Based on these resources the geomorphologic and geological heritage management model of the newly declared Geopark Villuercas-Ibores-Jara were also analyzed. Its main strengths are the geological heritage conservation, appreciation, study and dissemination in a sustainable nature tourism context.
\end{abstract}

KEY WORDS: Villuercas-Ibores-Jara, Geopark, Geological heritage, Sustainable tourism, Geosites 


\section{INTRODUCCIÓN}

El patrimonio natural, al igual que el cultural, es uno de los principales recursos susceptibles de ser explotado turísticamente (López Olivares, 1998; Chias, 2005). En este sentido, el primer precedente histórico de valorización del patrimonio natural per se, al menos desde un punto de vista legislativo, podría ser considerado la declaración de Yellowstone (Estados Unidos) como Parque Nacional en 1872, aunque inicialmente se hiciera con fines meramente conservacionistas, centrados en preservar la singularidad de sus formaciones naturales (Fortunato, 2005).

En el caso de España, a pesar de tener colgada la etiqueta del modelo de "sol y playa", el aprovechamiento turístico de espacios naturales cuenta con una gran tradición, que se remonta a principios del siglo XX, con la promulgación de la ley de Parques Nacionales de 1916 y la creación en 1905 de una Comisión Nacional encargada de organizar excursiones artísticas y de recreo, para fomentar la mejor apreciación de las bellezas artísticas y naturales nacionales entre los turistas extranjeros (Roca Fernández-Castanys, 2004).

A pesar de esa gran tradición, el aprovechamiento turístico de los espacios naturales protegidos de España ha sido tradicionalmente minoritario por diversas razones: a) La mala situación económica del país hasta la década de 1960 degeneró en que este tipo de turismo sólo pudiera ser practicado por élites sociales, tanto españolas como extranjeras; b) El aplastante auge del modelo de "sol y playa" ensombreció cualquier otro tipo de práctica turística; y c) El escaso desarrollo legislativo en materia de protección de espacios, que se ve evidenciado en el salto temporal entre la declaración de los dos primeros parques nacionales (Montaña de Covadonga y Ordesa) en 1918 y el tercero (Aigüestortes i Estany de Sant Maurici) en 1955.

Las décadas de 1980 y 1990 han sido claves en la valorización del binomio espacios naturales-turismo, propiciadas por la aparición de nuevas dimensiones de índole político-administrativa (Comunidades Autónomas y Unión Europea). A nivel nacional, existe una gran preocupación por la conservación de los valores naturales, observada en la promulgación de la ley 4/1989 de Conservación de los Espacios Naturales y de la Flora y Fauna Silvestres. A escala autonómica (Extremadura), se empieza a tomar conciencia de las posibilidades de desarrollo turístico, parejas a la declaración de espacio protegido de un territorio, ya sea por figuras autonómicas, adaptadas de la legislación nacional, o por figuras de protección internacionales, donde la Red Natura 2000 de la Unión Europea y las Reservas de la Biosfera y, más concretamente, la Red de Geoparques de la UNESCO juegan un papel predominante.

En 1996, durante la celebración del 30 Congreso Geológico Internacional en Beijing (China), surgió la idea de crear una red de geoparques, que colaborase en la protección y en la promoción del patrimonio geológico a través del desarrollo económico sostenible de sus territorios (Zouros, 2004). Fruto de esta idea se creó en 1997 un Programa de Geoparques por la UNESCO, que acabaría convirtiéndose en la 
actual Red Global de Geoparques conformada por 77 geoparques de 25 países. En el año 2000 nace la European Geopark Network (EGN), red de geoparques europeos unidos para proteger y promocionar el patrimonio geológico a partir de una gestión común, así como para contribuir al intercambio de información y experiencias exitosas. La EGN está compuesta actualmente por 52 miembros pertenecientes a 18 países.

El programa Geoparque representa una nueva alternativa para el reconocimiento de áreas que poseen algún valor geológico, así como de tipo ecológico en general. Bajo el nombre de Geoparque Europeo se designa a un territorio de límites bien definidos y con unas características concretas, que ofrece un patrimonio geológico particular y una estrategia de desarrollo económico sostenible (Zouros y Martini, 2003). Actualmente en España existen 8 espacios naturales que ostentan la categoría de geoparque: el Parque Cultural del Maestrazgo, el Parque Natural de Cabo de Gata-Níjar, el Parque Natural de las Sierras Subéticas, la comarca de Sobrarbe, la Costa Vasca, la Sierra Norte de Sevilla, la comarca Villuercas-Ibores-Jara y el recién declarado Geoparque Cataluña Central (Fuente: http://www.europeangeoparks.org [consultado: 26/01/2013]).

Las repercusiones socioeconómicas de la declaración de un territorio como Geoparque, unida al fomento y puesta en venta del geoturismo como principal producto turístico, fueron analizadas por Farsani et al. (2011) en 25 geoparques de la EGN. En ellos se creó un promedio aproximado de 18 empleos locales estables y 9 estacionales en cada geoparque, al margen del empleo indirecto no cuantificado. El $68 \%$ de los geoparques promueven el desarrollo de actividades turísticas locales: observación de aves, viajes en barco, rutas a pie, etc. Un $36 \%$ de ellos fomentan, además, la venta de productos locales, bien sea mediante marketing directo o mediante la creación de denominaciones de origen o novedades en el etiquetado, que permitan identificar el producto con el espacio protegido. A este éxito observado en la mitad de los geoparques miembros de la EGN hay que añadirle el esfuerzo económico, publicitario y logístico de las administraciones públicas nacionales, autonómicas, provinciales, supramunicipales y locales, así como el de sectores privados.

Estas tendencias relativas a la valorización de recursos patrimoniales y sus formatos de interpretación, en el caso de la Comunidad Autónoma de Extremadura, han sido objeto de atención, desde 1998, mediante una serie de instrumentos de intervención turística, entre los que destacan los Planes de Excelencia Turística centrados en la promoción de ciudades-, así como los Planes de Competitividad Turística y los Planes de Cooperación Transfronteriza con Portugal, orientados éstos al aprovechamiento turístico del río Tajo y del embalse del Alqueva. De forma más específica, los aspectos de revalorización patrimonial están contenidos en Planes de Dinamización del Producto Turístico (PDPT), enfocados a la consolidación de destinos urbanos y a la promoción de comarcas emergentes al turismo.

En este contexto, el PDPT Villuercas-Ibores-Jara supuso una inversión inicial de 2,7 millones de euros, desde 2007, con el objetivo de mejorar la calidad de los servicios 
turísticos, así como el medio urbano y natural de los municipios afectados. Una de las políticas estrellas surgidas durante este plan fue el desarrollo y la puesta en marcha de la candidatura de la comarca Villuercas-Ibores-Jara para formar parte de la EGN. Este esfuerzo institucional fue claramente comandado por la Diputación Provincial de Cáceres, apoyado en el conocimiento de expertos locales en geología de la zona, ligados al mundo de la enseñanza y de la investigación universitaria y miembros de la Asociación Geológica de Extremadura (AGEx) y de la Universidad de Extremadura (UEX). En la actualidad se sigue trabajando en la promoción de los geositios, acondicionamiento de accesos, señalización de rutas y diseño de paneles informativos, entre otras tareas encaminadas a la captación de visitantes.

Villuercas-lbores-Jara abarca un espacio con unos importantes recursos geológicos y ambientales declarado geoparque de la Red Europea de Geoparques en septiembre de 2011, tras una serie de pasos llevados a cabo por las administraciones (descritos en Pulido et al., 2011). Se entiende esta figura como la protección de un territorio que comprende uno o más sitios de gran importancia científica, no sólo por razones de tipo geológico sino en virtud de su valor arqueológico, ecológico y cultural (UNESCO, 1999). En un Geoparque se demuestran los métodos para la conservación del patrimonio geológico, así como también se desarrollan métodos para la enseñanza de disciplinas geo-científicas y aspectos ambientales más amplios.

La inclusión de la comarca en la EGN supone un paso más hacia adelante para conseguir los objetivos de fomento del turismo de naturaleza, propuestos por el gobierno autonómico en la Estrategia para el Desarrollo Sostenible de Extremadura (2011) y en el Plan Estratégico de Turismo para Extremadura 2010-2015 de la Dirección General de Turismo de Extremadura (2010). En este sentido han de mencionarse también otras líneas de actuación que la Diputación Provincial de Cáceres mantiene para el impulso socioeconómico sobre espacios protegidos, como es el caso del Parque Natural de Tajo Internacional, incluido en la estrategia de cooperación transfronteriza con Portugal, o el del Parque Nacional y la Reserva de la Biosfera de Monfragüe y el impulso para la adhesión a la Carta Europea de Turismo Sostenible.

El nivel de protección del territorio afectado por Las Villuercas lo conforman distintas figuras: 7 Zonas de Especial Protección de Aves, 8 Lugares de Interés Comunitario, el Corredor Ecológico y de Biodiversidad del Río Guadalupejo, 3 Árboles Monumentales y un área perteneciente a la Reserva de la Biosfera de Monfragüe, entre otros espacios (explicados con mayor detalle en el capítulo 3). Aunque éstas no consideran los valores geológicos como motivo de conservación, exceptuando el Monumento Natural de la Cueva de Castañar de Ibor. Sin embargo, los valores que ofrece este territorio son, sin duda, sus características naturales diferenciadoras, tanto por microclima como por el régimen hídrico, que unido a la estructura geológica y geomorfológica, conforman una comunidad biótica con identidad propia, que también ha estado presente en la cultura y socioeconomía desde tiempos pasados, y aún se mantiene como legado histórico que ha de ser conservado. 
Existe otro objetivo añadido que se refiere a una estrategia de desarrollo socioeconómico sostenible. La comarca engloba a 25 núcleos (municipios y entidades locales menores) y alrededor de 14.000 habitantes. Esta escasa población, unido a una extensión apreciable de $2544 \mathrm{Km}^{2}$, siendo el municipio de Alía el que más extensión ocupa con prácticamente $600 \mathrm{~km}^{2}$, hace que el territorio tenga una densidad de población muy baja, inferior a la media nacional, regional y provincial. A ello hay que añadir el alto envejecimiento de la población, que soporta los valores más altos de la provincia con un $38,8 \%$. El sector primario es la base de la economía, siendo la ganadería ovina y caprina y la agricultura basada en el olivo, la viña y la castaña las principales actividades generadoras de empleo. Estas características demográficas y económicas requieren de nuevas fórmulas que reactiven el tejido productivo y frenen la tendencia regresiva de la población. Y para ello se hace necesario impulsar nuevas actividades en consonancia con las potencialidades del territorio.

La comarca alberga una gran cantidad de recursos potenciales para su desarrollo turístico, aunque ciertas debilidades como su escasa oferta turística, unido a unas vías de comunicación hasta hace pocos años en un estado deficiente (Mora et al., 2003), la han convertido en una zona poco atractiva para el visitante. En este contexto, y con una sociedad actual que anhela disfrutar de la naturaleza, y demanda, cada vez más, servicios turísticos de calidad, se hace necesario dar a conocer los recursos naturales, para que puedan ser demandados por el turista y disfrutados, así como acondicionar de forma competitiva la oferta de servicios turísticos.

El patrimonio geológico forma parte de esos recursos naturales con potencialidad turística (Romero y Belmonte, 2002), y está constituido por los recursos no renovables de valor científico, cultural o educativo y de interés paisajístico recreativo, ya sean formaciones rocosas, estructuras geológicas, formas de relieve, acumulaciones sedimentarias, ocurrencias minerales, paleontológicas y otras, que permitan reconocer, estudiar e interpretar la evolución de la historia geológica de la tierra y los procesos que la han modelado (Domínguez y Rodríguez, 2007). Según el carácter no renovable de dichos recursos, su conservación y protección requiere una gestión que permita su catalogación, difusión y protección (Villalobos, 2000).

\section{DESCRIPCIÓN GEOGRÁFICA Y GEOLÓGICA DEL GEOPARQUE}

La delimitación territorial del Geoparque coincide en la actualidad con la superficie de la Mancomunidad Integral Villuercas-Ibores-Jara, formada por 19 municipios. Se encuentra situada al SE de la provincia de Cáceres y próxima al límite provincial con Badajoz, Toledo y Ciudad Real. Conforma una unidad geográfica constituida por elementos físicos, económicos y culturales homogéneos bien definidos. Sus condiciones físicas son a priori desfavorables para el desarrollo: la agricultura tradicional está en crisis y el sector industrial y terciario son muy débiles. Esta área registra una baja densidad de población $\left(5,5 \mathrm{hab} / \mathrm{km}^{2}\right)$, altas tasas de envejecimiento $(38,8 \%)$ y bajas tasas de infancia y juventud $(7,4 \%$ y $13,4 \%$, respectivamente). Los efectos demográficos de estos indicadores son la continua pérdida de población (3.002 
personas desde 2000 a 2010) parejo a otros impactos socioeconómicos muy negativos como la falta de espíritu empresarial.

A pesar de su pequeño tamaño $\left(2.544 \mathrm{~km}^{2}\right)$ y sus debilidades económicas, esta área muestra una amplia gama de recursos naturales. Una complicada historia geológica ha dado lugar a una gran variedad de atractivos paisajes basados en la singularidad de las formaciones típicas de estilo apalachense (Gómez Amelia, 1985), como se puede observar en el esquema de la Figura 1. El relieve es el resultado de la erosión diferencial en dos tipos de roca dominante: cuarcita armoricana (Ordovícico Inferior, $485 \mathrm{Ma}$ ) y materiales precámbricos como esquisto, pizarra o grauvaca (Grupo Domo Extremeño, CEG), y un posterior efecto tectónico o estructural después de la orogenia alpina (60 - $2 \mathrm{Ma}$ ). Este tipo de formaciones y paisajes poseen un gran interés, desde el punto de vista paisajístico y geológico, debido a su rareza, con formaciones similares presentes en muy pocas partes del mundo, a lo que hay que añadir el valor de algunas de sus partes altas, accesibles en coche, como p. ej. El pico de La Villuerca, como miradores naturales del terreno.

Figura 1. Esquema del relieve Apalachense característico de Villuercas-Ibores-Jara.

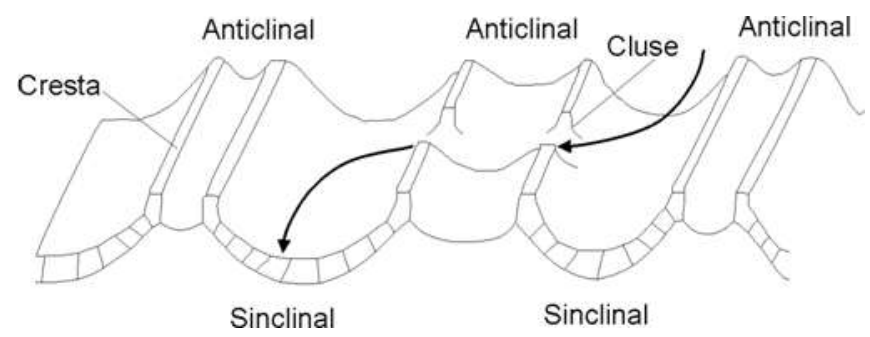

Geológicamente, Villuercas-Ibores-Jara constituye un sistema montañoso de edad paleozoica, formado por unas de las rocas más antiguas de España (650 - 400 $\mathrm{Ma})$, rodeado de dos graben de Edad Terciaria, ríos Tajo y Guadiana, en el norte y sur del sistema, respectivamente, y por penillanuras extensas de edad precámbrica en el lado este y oeste. Su topografía se caracteriza por unas montañas paralelas (sierras) y valles alineados en dirección NO-SE (Armoricana) levantados durante el movimiento orogénico herciniano y arrasado por la erosión durante la era Mesozoica. Estos valles son un lugar inmejorable para practicar actividades como el senderismo, gracias a más de 10 rutas señalizadas, entre las que destacan las que tienen como punto de llegada el Monasterio de Guadalupe y la visita de la Virgen, patrona de Extremadura. Este tipo de peregrinación religiosa está actualmente promoviéndose mediante carteles informativos y diseño de rutas desde numerosas partes de la región extremeña. 
Figura 2. Descripción geológica del área de estudio.

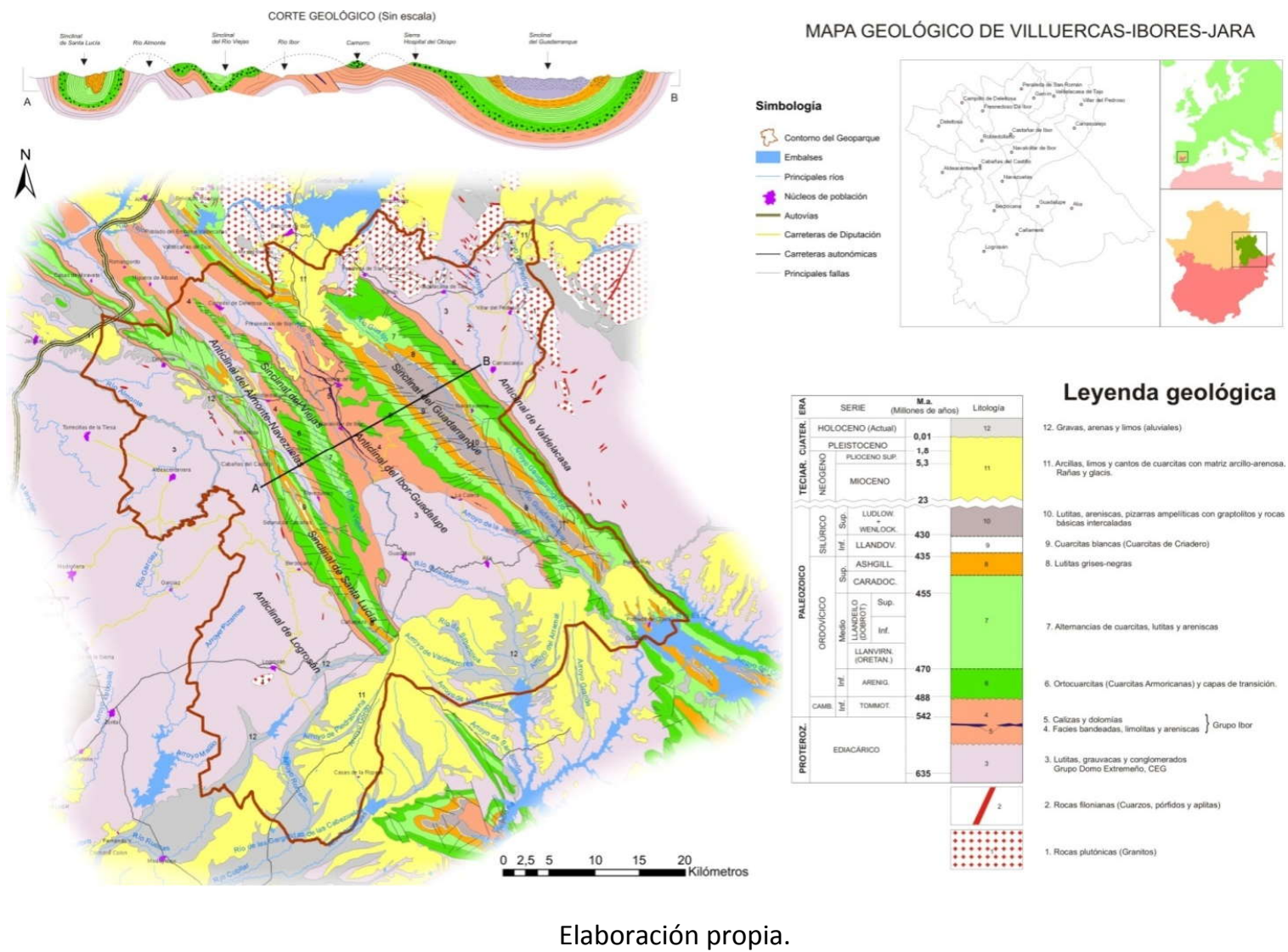

Es muy importante conocer como fue la historia geológica del Geoparque para entender el resultado final que es el relieve actual. Se podría hablar de una tierra emergida en el Proterozoico (Era Neoproterozoica, y concretamente el Ediacárico, periodo aprobado en 2004 por la "International Comission on Stratigrafy" (ICS)). Este periodo es muy importante en el Geoparque porque los fósiles más antiguos se han encontrado en este periodo (620-452). En ese momento en el que emergió del mar una banda arqueada de noroeste a sureste (de la actual Península Ibérica) del gran supercontinente Gondwana, formada por pizarras y gneis. Este macizo precámbrico fue arrasado posteriormente por la erosión y cubierto casi en su totalidad por el mar (Figura 3). En la actualidad, un total de 9 geositios destacan por la presencia de fósiles precámbricos, aunque la mayor parte de ellos están restringidos a las visitas turísticas. No obstante, ejemplos característicos de los fósiles pueden ser observados en el Centro de Interpretación del Geoparque, de reciente creación, localizado en el núcleo urbano de Logrosán. 
Figura 3. PROTEROZOICO. Entre hace 2.500 y 570 M.a.

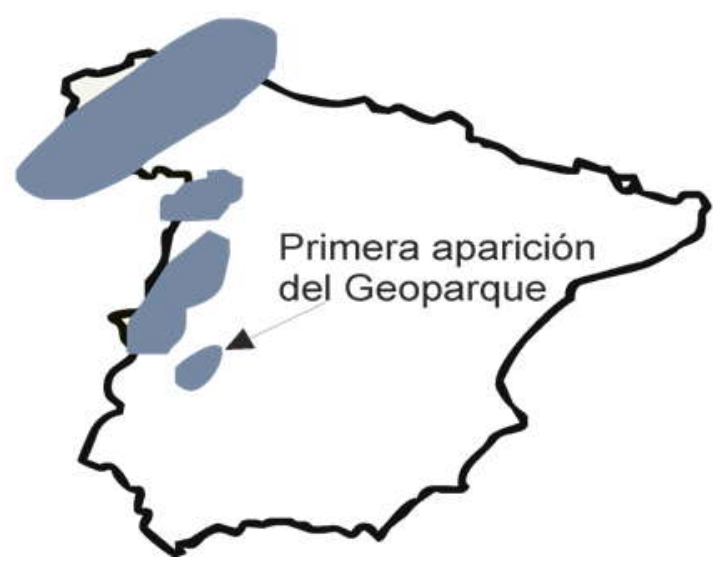

Elaboración propia

En el Paleozoico los mares que cubrían la actual península estaban llenos de sedimentos provenientes de la deposición de materiales arrancados al macizo precámbrico. Estos materiales, principalmente pizarras y cuarcitas, se plegaron cuando ocurrió el movimiento de la Orogenia Herciniana, en los periodos DevónicoCarbonífero, sometiendo a esos materiales sedimentados a un proceso de fuerte compresión que dará lugar a un fuerte plegamiento, elevando cordilleras. Entre ellas a lo que hoy conocemos como Macizo de Las Villuercas (Figura 4 y 5), que queda emergida desde hace 300 M.a. Posteriormente este macizo fue arrasado por un largo periodo de erosión (Figura 6 ) en el que no se produjo sedimentación marina. En este periodo que eliminó los materiales geológicos desde el Devónico hasta todo el Paleozoico, y Mesozoico. Un claro testimonio de esos plegamientos puede ser observado en el geositio no 21 "Apreturas del río Almonte".

Figura 4. PALEOZOICO. Entre hace unos 600 y unos 225 M.a.

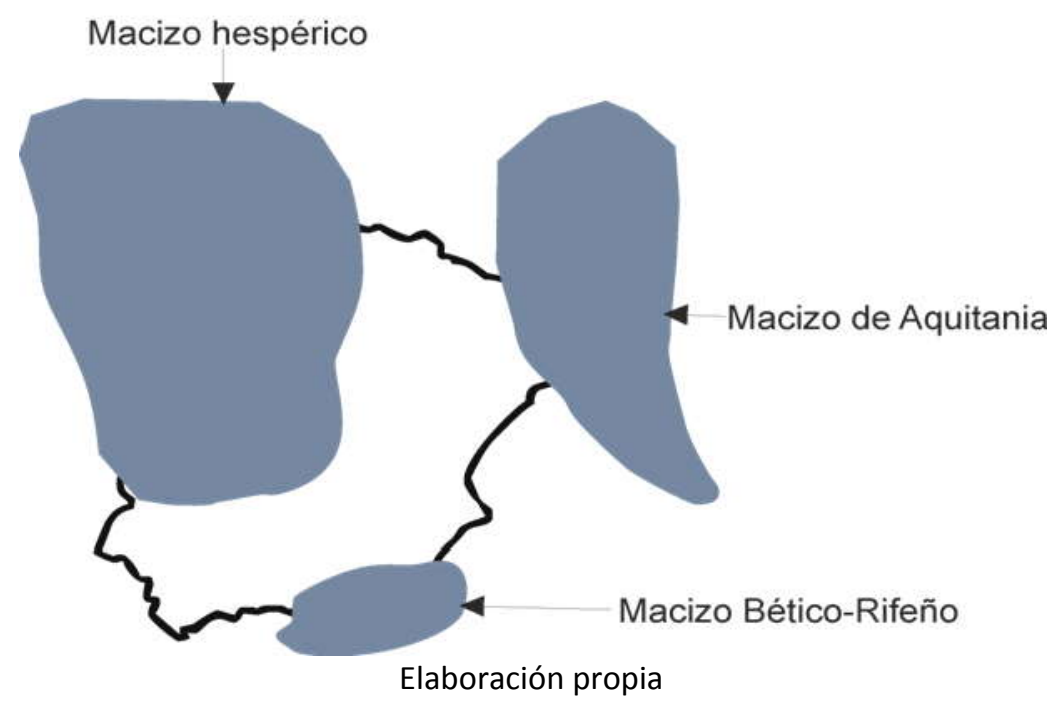

Investigaciones Turísticas 
Figura 5. Relieve “Estilo Jurásico" (Orogenia Hercínica).

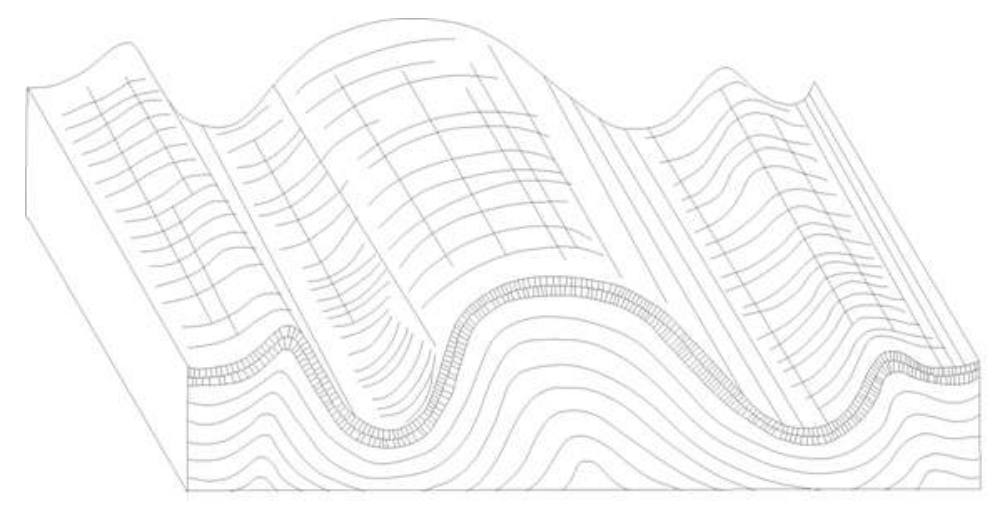

Elaboración propia a partir de trabajos inéditos de Juan Gil Montes.

El Mesozoico es un periodo en el que predomina la erosión y la sedimentación, con transgresiones y regresiones marinas, que produjeron la acumulación en el borde oriental (el zócalo basculaba hacia allí) de materiales sedimentarios plásticos, principalmente calizas y areniscas (Figura 7). Sin embargo, en el zócalo hercínico, sobre el que se asentaba el actual Geoparque, no se produjo ningún tipo de sedimentación.

Figura 6. Relieve arrasado por la erosión (Paleozoico y Mesozoico).

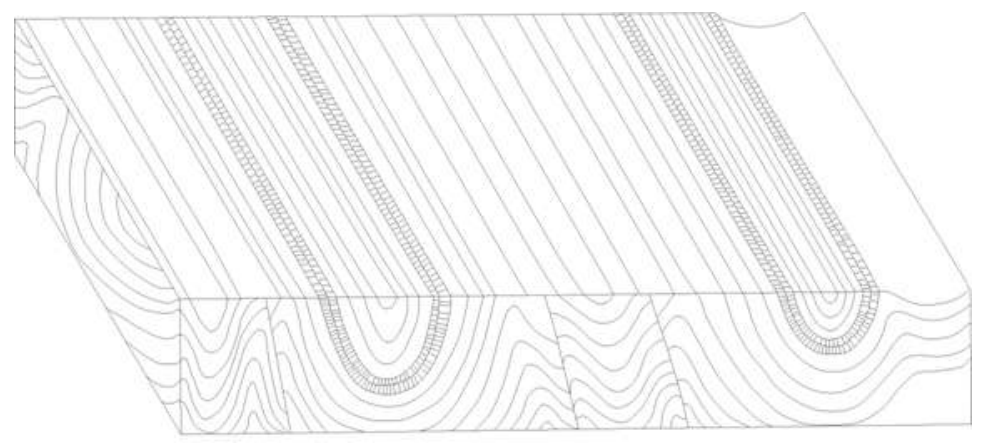

Elaboración propia a partir de trabajos inéditos de Juan Gil Montes. 
Figura 7. MESOZOICO. Entre hace unos 225 y 65 M.a.

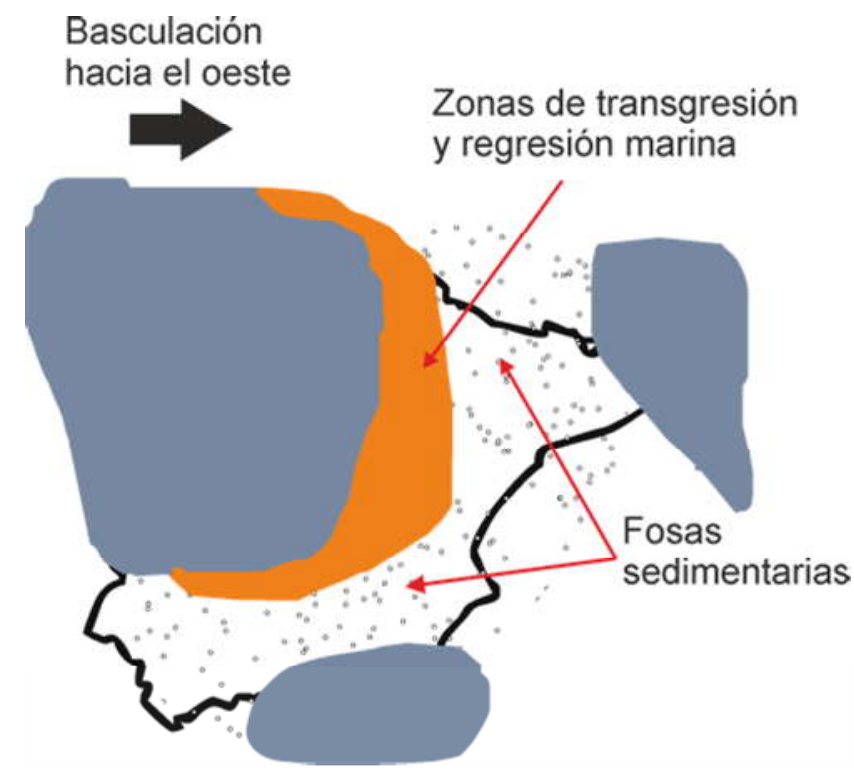

Elaboración propia

Es en el Cenozoico cuando se produjo la Orogenia Alpina (Figura 8), que formó las cordilleras más recientes de la Península Ibérica y las depresiones paralelas a las mismas y la configuración actual de La Meseta, que pasó a inclinarse hacia el Atlántico y con ello buena parte de los ríos peninsulares. El zócalo de La Meseta estaba formado por materiales muy antiguos y rígidos, fracturándose y dando lugar a bloques levantados y hundidos (relieve de estilo "germánico"). En uno de los bloques levantados se formaron las sierras interiores de La Meseta, como los Montes de Toledo (donde se encuentra el actual Geoparque). Los bloques hundidos crearon las cuencas sedimientarias de la Meseta, como la del Tajo y Guadiana, que se llenaron de sedimentos aportados por la erosión de las cordilleras circundantes. Por último, en el período Cuaternario, la red fluvial se encajó en el terreno, configurando la geomorfología actual de la región. También en el Cuaternario se produce la meteorización mecánica sobre las cumbres de cuarcitas que se depositan en bloques cuarcíticos en las laderas de las sierras. Son las conocidas como "pedreras" tan representativas del Geoparque. Sobre una de estas pedreras se encuentra el geositio no 11: "Nacimiento del río Almonte" (accesible en coche). 
Figura 8. CENOZOICO. Entre hace unos 65 y 1,7 M.a.

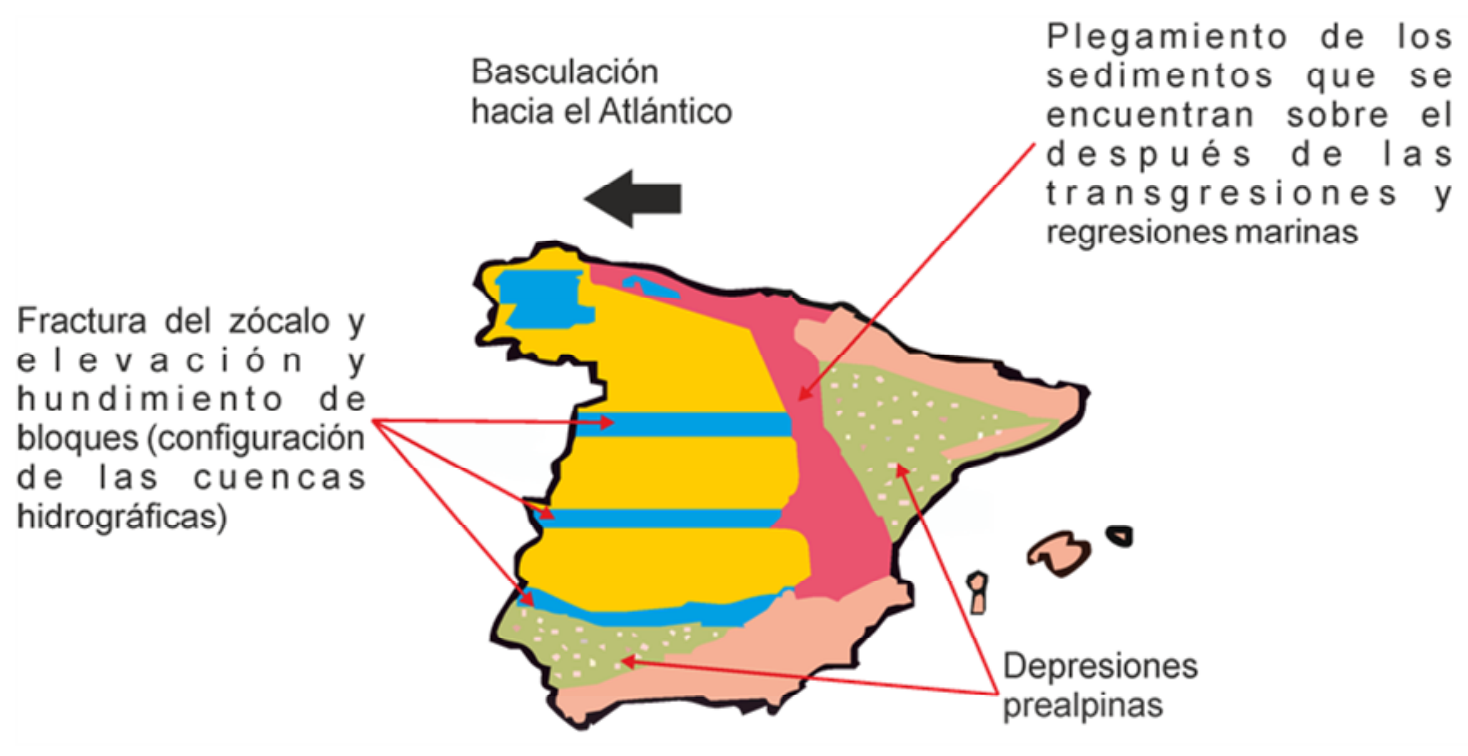

Elaboración propia.

La evolución geológica ha dado como resultado tres formas de modelado que caracterizan el relieve de la zona:

[a] La penillanura circundante, formada por lutitas y areniscas de la era precámbrica, se extiende alrededor del sinclinal paleozoico de Las Villuercas. En la zona oriental se pueden destacar el anticlinal de Valdelacasa y su nivelado de batolitos de granito.

[b] El relieve apalachense característico, formado por alineaciones de sierras de cuarcita como principal elemento del relieve, donde afloran las cuarcitas armoricanas y areniscas. Está caracterizada por fuertes pendientes terminadas en cresta, picos o peñascos. Estas formas han sobrevivido debido a la dureza de sus materiales.

[c] Los valles interiores, producto del encaje de la red fluvial de los ríos Gualija, Ibor, Viejas, Almonte, Cuernacabras y Garganta de Santa Lucía (afluentes del río Tajo), Guadarranque, Guadalupejo y Ruecas (afluentes del río Guadiana). 
Figura 9. Relieve apalachense actual del Geoparque.

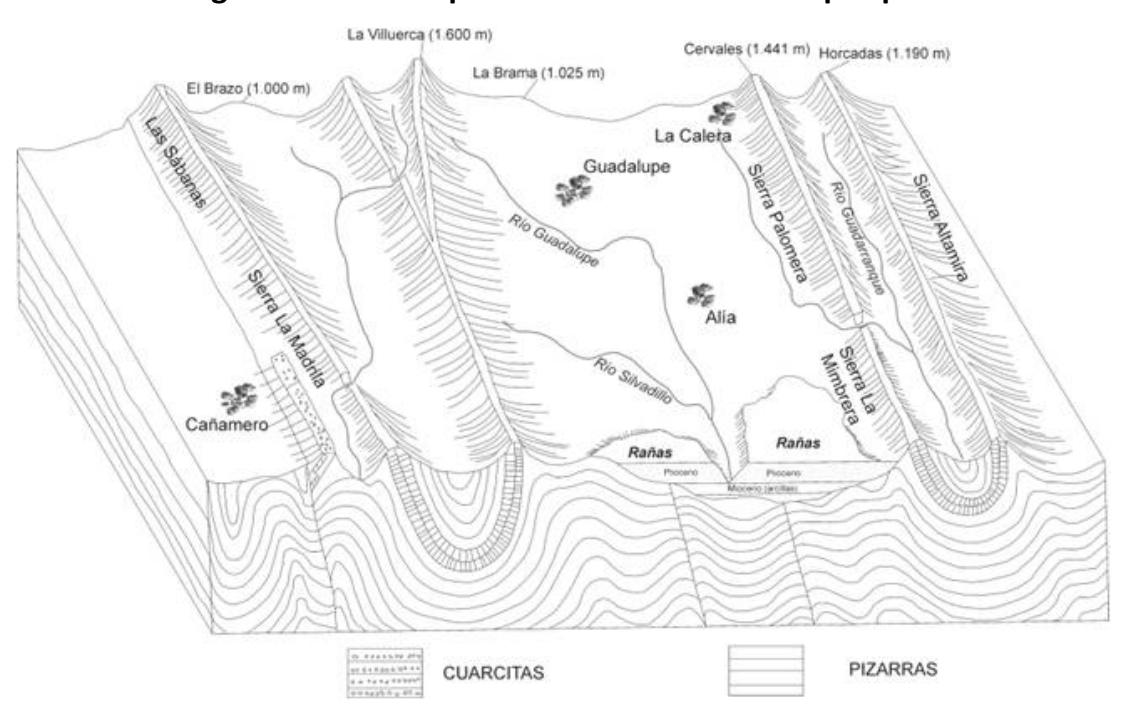

Elaboración propia a partir de trabajos inéditos de Juan Gil Montes

\section{VALORACIÓN DEL PATRIMONIO GEOLÓGICO Y NATURAL}

Se entiende por geositio un lugar geológico excepcional, geográficamente bien delimitado y que presenta un valor singular desde un punto de vista científico, pedagógico, cultural o turístico (Brilha, 2005). Los sitios geológicos de VilluercasIbores-Jara fueron escogidos según criterios científicos basados en opiniones de expertos con un gran conocimiento de la geología de la zona. Para su propuesta se formó un comité científico y educativo, compuesto por especialistas pertenecientes a la Asociación Geológica de Extremadura (AGEX) y prestigiosos investigadores de la Universidad de Extremadura.

Paralelamente se realizó una exhaustiva revisión bibliográfica: memorias de mapas geológicos, artículos de revistas, manuales, etc. Esta fase del trabajo fue llevado a cabo por técnicos pertenecientes al Área de Desarrollo Local de la Diputación de Cáceres y por investigadores de la Universidad de Extremadura (los autores del artículo entre ellos). Un total de 44 sitios geológicos fueron seleccionados después de un proceso de evaluación cualitativa, de acuerdo con sus valores ecológicos, educativos o turísticos, teniendo en cuenta aspectos fundamentales como la historia geológica, estratigrafía, petrología, la paleontología, geomorfología tectónica, o la minería. Estos sitios geológicos fueron georreferenciedo por un GPS de mano y cartografiados (Figura 10). 
Figura 10. Localización geográfica de los geositios.
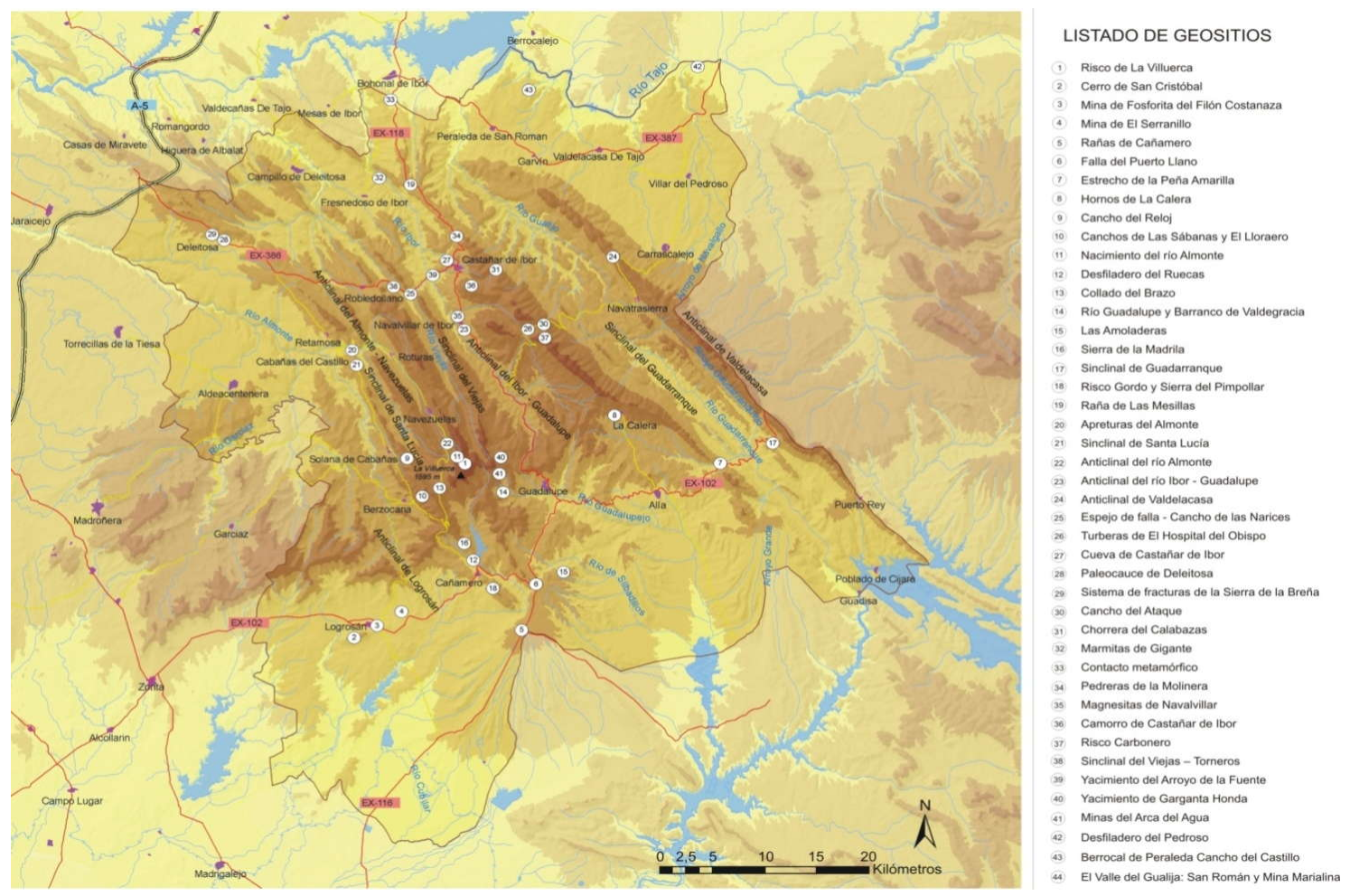

Elaboración propia.

En este trabajo se exponen únicamente los 15 geositios que bajo criterio de los autores tienen una valoración cualitativa superior, atendiendo a su alto valor científico, cultural o paisajístico. Posteriormente se realizó una caracterización de los geositios seleccionados, que consistió en un estudio en detalle de las características geológicas más importantes, así como una clasificación de los valores turísticos potenciales, en los que se contemplaron aspectos como la estética, la accesibilidad al lugar o la capacidad de carga soportable, y cuyo resultado se presenta en la Tabla 1.

Los 15 geositios que se han destacado tienen un gran interés geológico y geomorfológico, algunos de ellos de gran singularidad, los cuales se encuentran en buen estado de conservación, debido fundamentalmente a que no han sufrido impactos importantes derivados de actividades turísticas u otros usos. La realidad es que prácticamente todo el área del Geoparque posee unos recursos naturales de gran importancia para el desarrollo del turismo, integrados en una variedad de ecosistemas de gran valor ecológico. Además, la existencia de varios espacios naturales protegidos indica el grado de preocupación por la conservación de los recursos naturales de la zona, cuya población aprovecha de manera sostenible para la elaboración de productos forestales y agroalimentarios de gran calidad, así como el desarrollo de actividades cinegéticas. La ausencia de actividades industriales de importancia y la orografía de la zona, que ha limitado la existencia de grandes poblaciones que hayan 
podido modificar sensiblemente los ecosistemas, ha influido plenamente para que exista un grado de conservación alto del medio ambiente.

Uno de los valores adicionales del territorio se debe a la riqueza del patrimonio natural zoológico y botánico del territorio, reconocido a través de numerosas figuras de protección del territorio por parte de las directivas comunitarias y la legislación autonómica: [a] 7 zonas ZEPA: Sierra de las Villuercas, Puerto Peña y Sierra de los Golondrinos, Llanos de Zorita y embalse de Sierra Brava, Riberos del Almonte, Embalse de Valdecañas, Monfragüe y las dehesas del entorno y Vegas del Ruecas, Cubilar y Moheda Alta; [b] 5 LIC: Río Guadalupejo, Río Ruecas Alto, Sierra de Cabezas de Águila, Dehesas del Ruecas y del Cubilar y Río Almonte; [c] un Corredor Ecológico y de Biodiversidad: Río Guadalupejo; [d] 3 árboles monumentales y singulares: Roble de la Nava, Lorera de la Trucha y castaños de Calabazas, el Refugio del alto de San Blas, el Túnel de Cañamero y, de manera especial, [e] un monumento natural: la Cueva de Castañar de Ibor y [f] la pertenencia a la Reserva de la Biosfera de Monfragüe.

El rico patrimonio faunístico viene generando en los últimos años un creciente turismo ornitológico atraído por algunas especies emblemáticas como las abundantes grullas que se concentran al sur del territorio y las rapaces ligadas a los afloramientos cuarcíticos de las sierras, buitres leonados (Gyps fulvus) y negros (Aegypius monachus), alimoches (Neopron percnopterus), cigüeñas negras (Ciconia nigra), búhos (Bubo bubo) y águilas reales (Aquila chrysaetos), etc.

El pico culminante de este macizo orográfico es "La Villuerca" (Figura 11) que, con 1601 metros de altitud, da nombre en la actualidad a toda la comarca. Al sur de este pico de dos cumbres se encuentra un amplio paisaje de rañas, dominado por extensas superficies de olivar. Es un punto de interés geológico singular. Al espacio, además, le complementan unas excelentes vistas panorámicas del valle del río lbor, de las rañas y de los relieves villuerquinos, origen de estos sedimentos terciarios (Figura 12).

Figura 11. Pico “La Villuerca”.

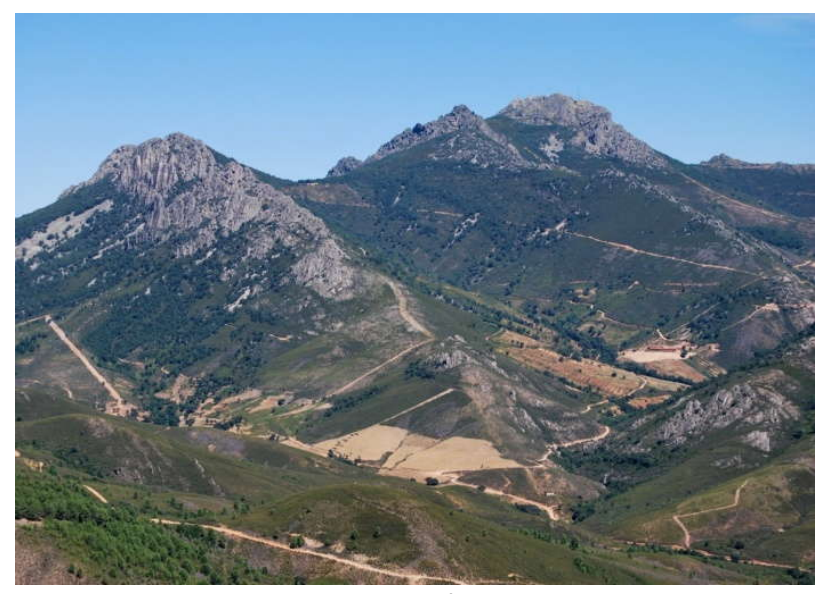

Autor: Juan Gil Montes. 
Figura 12. Rañas de las mesas de Cañamero y Alía.

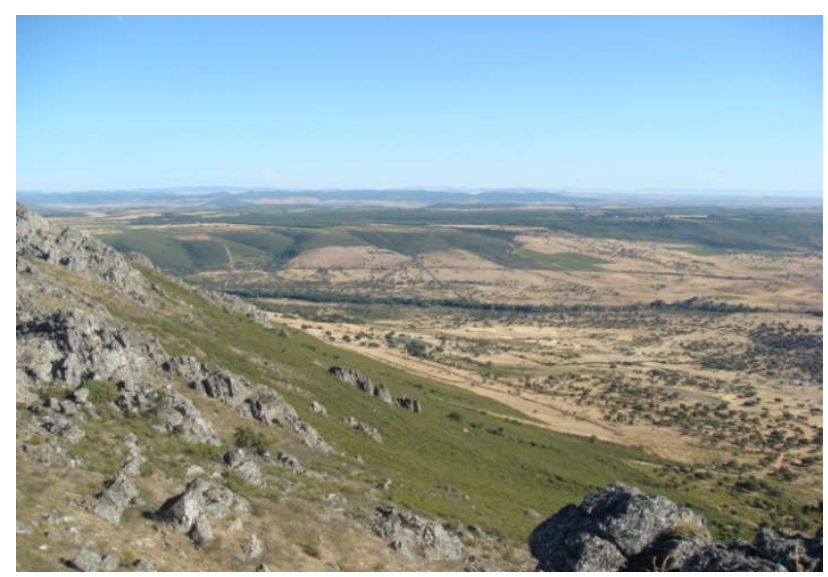

Autor: Juan Gil Montes

El Cerro de San Cristóbal es un pequeño afloramiento de roca granítica situado cerca de la localidad de Logrosán, que alberga una antigua mina de fosforita (Figura 13). Cuenta con construcciones singulares a base de ladrillo y pizarra. El entorno tuvo una gran importancia minera en el pasado, que se remonta al tercer milenio antes de Cristo, con el poblamiento del Cerro de San Cristóbal y la extracción de metales. En la localidad de Alía se encuentra un encajamiento fluvial con profundo desfiladero del río Jarigüela, que conforma una fractura transversal de crestones de cuarcitas donde se pueden apreciar hendiduras en la roca. Este batolito se adentra en el interior de la corteza, siendo imposible conocer con exactitud su tamaño y profundidad. Los procesos erosivos desmantelaron las rocas que lo cubrían dejando al descubierto el actual cerro de granito (Figura 14).

Figura 13. Cerro de San Cristóbal.

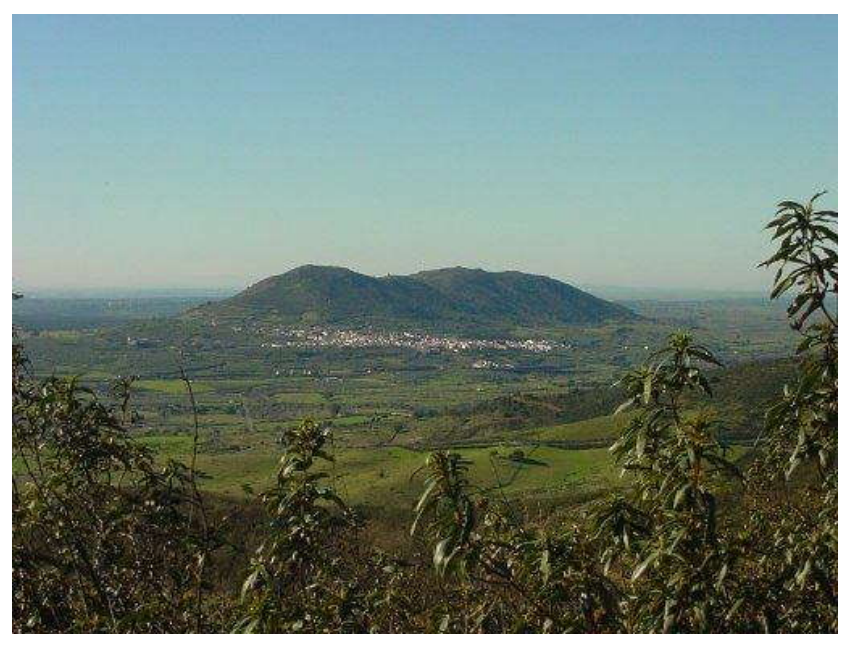

Autor: Juan Gil Montes 
Figura 14. Esquema de la evolución geológica del Batolito de San Cristobal
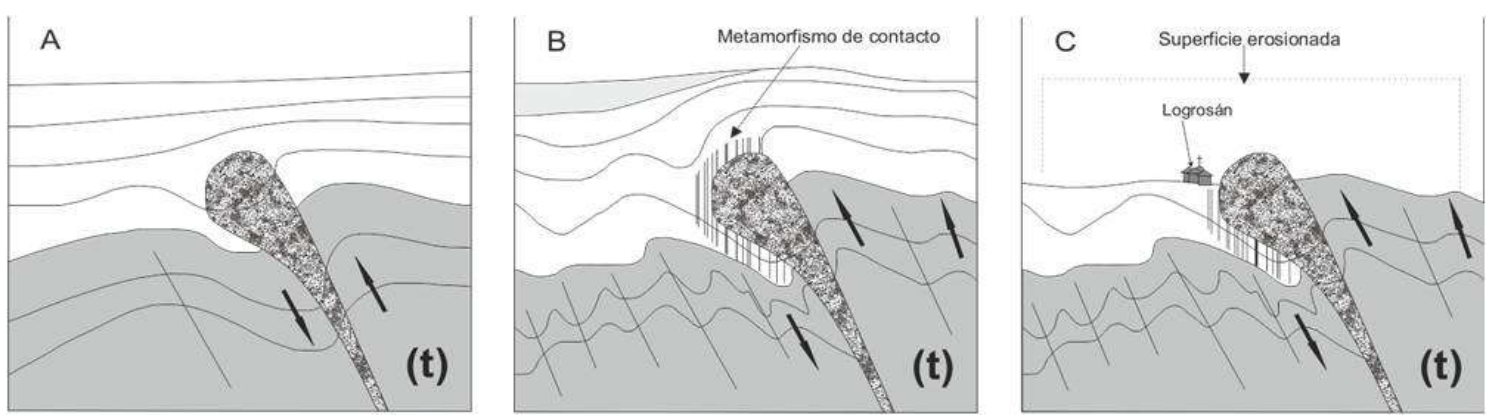

En el término municipal de Navezuelas se sitúa el nacimiento del río Almonte, que encuentra sus primeras corrientes debajo de una pedrera de bloques de cuarcitas que han sido desprendidas de las cumbres a causa de la meteorización mecánica que se dio en el Cuaternario (Figuras 15 y 16). También encontramos el Anticlinal del Río Almonte, que circula paralelo a su cumbre hasta la localidad de Roturas. Se trata de uno de los claros ejemplos de relieve invertido de Las Villuercas (Figura 17).

Figura 15. Nacimiento del río Almonte y "pedreras".

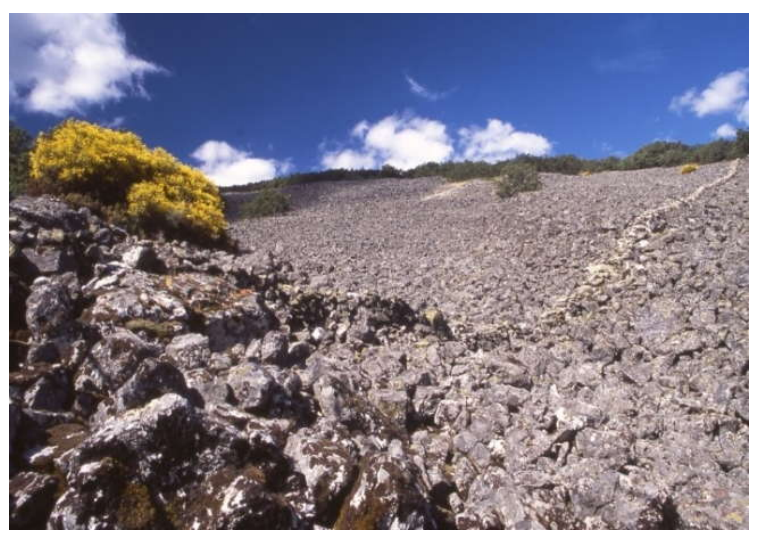

Autor: Juan Gil Montes. 
Figura 16. Formación de las "pedreras” y nacimiento del río Almonte.

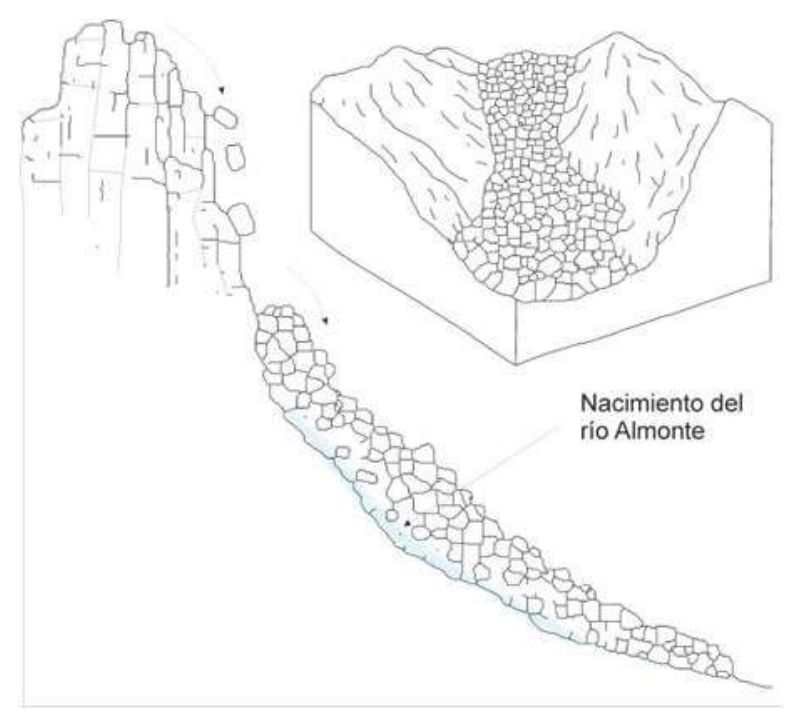

Elaboración propia.

Figura 17. Anticlinal del Río Almonte.

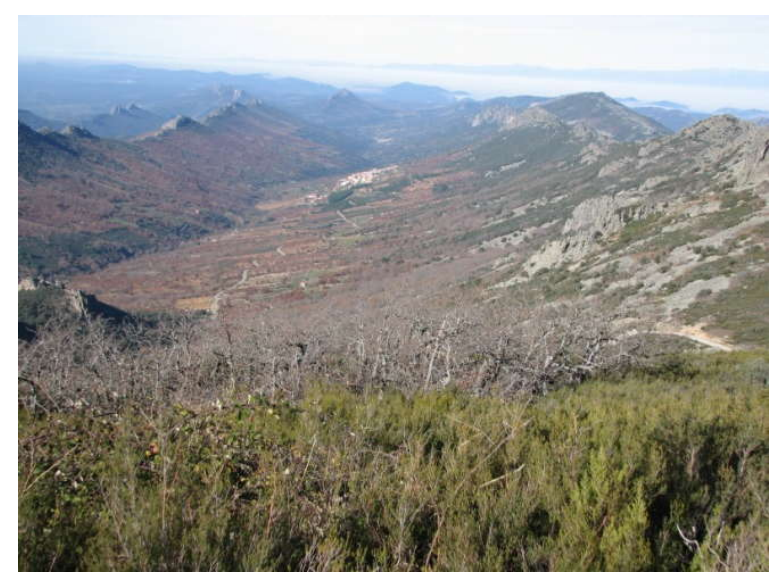

Autor: Juan Gil Montes.

El Anticlinal del Ibor-Guadalupe es un valle fluvial entre alineaciones cuarcíticas cuya anchura varía de unos $10 \mathrm{~km}$., desde la Calera a Guadalupe, hasta $5 \mathrm{~km}$. en la zona de Castañar de Ibor (Figura 18). Por otra parte, el Sinclinal de Santa Lucía-Río Ruecas expone flancos de "cuarcitas armoricanas" a unas alturas de entre 800 y 1600 $m$. En una de sus cumbres se encuentra el castillo árabe de Cabañas, del que es posible divisar el espectacular valle fluvial entre alineaciones cuarcíticas (Figura 19). 
Figura 1. Anticlinal de Ibor-Guadalupe.

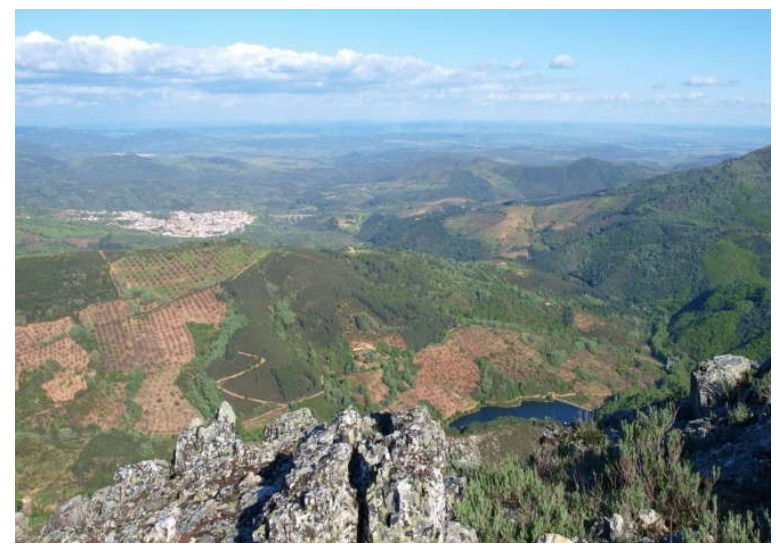

Autor: Juan Gil Montes.

Figura 19. Sinclinal de Santa Lucía y Castillo de Cabañas.

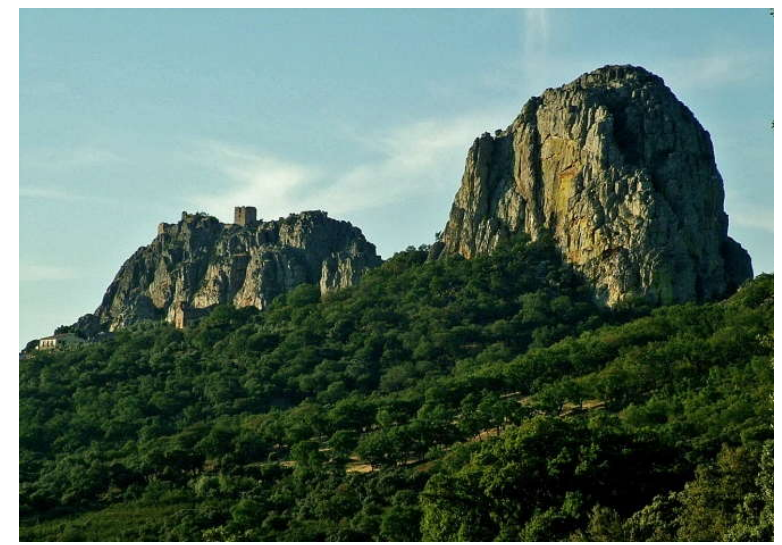

Autor: Juan Gil Montes.

En la Figura 20 se muestra un claro ejemplo de deformación rocosa por plegamiento. El principal elemento del relieve de Las Villuercas lo conforman las "cuarcitas armoricanas" del periodo ordovícico, que originan alineaciones montañosas o "Sierras" de dirección NW-SE, caracterizadas por la fuerte inclinación de sus laderas y por la terminación en "cresta", "pico" o "risco" de los niveles cuarcíticos que las culminan. El geositio de mayor fragilidad y también de mayor valor geológico es el Monumento Natural de la "Cueva de Castañar" (Figuras 21 y 22). Se trata de una cavidad con un impresionante abanico de espeleotema que, además, son muy poco frecuentes en el mundo, con formas finas y delicadas de aragonitos. Los colores claros que contrastan con los tonos rojizos y oscuros de las pizarras y arcillas que los rodean, hacen destacar aún más la belleza de la formación cárstica. 
Figura 20. Portilla del Almonte.

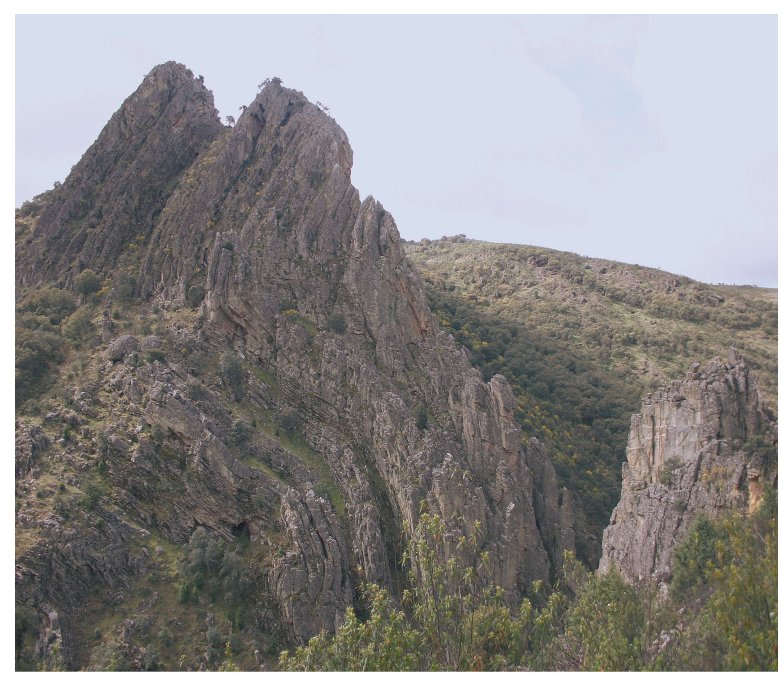

Autor: Juan Gil Montes.

Figura 21. Formas kársticas de aragonito del Monumento Natural de la Cueva de Castañar de Ibor.

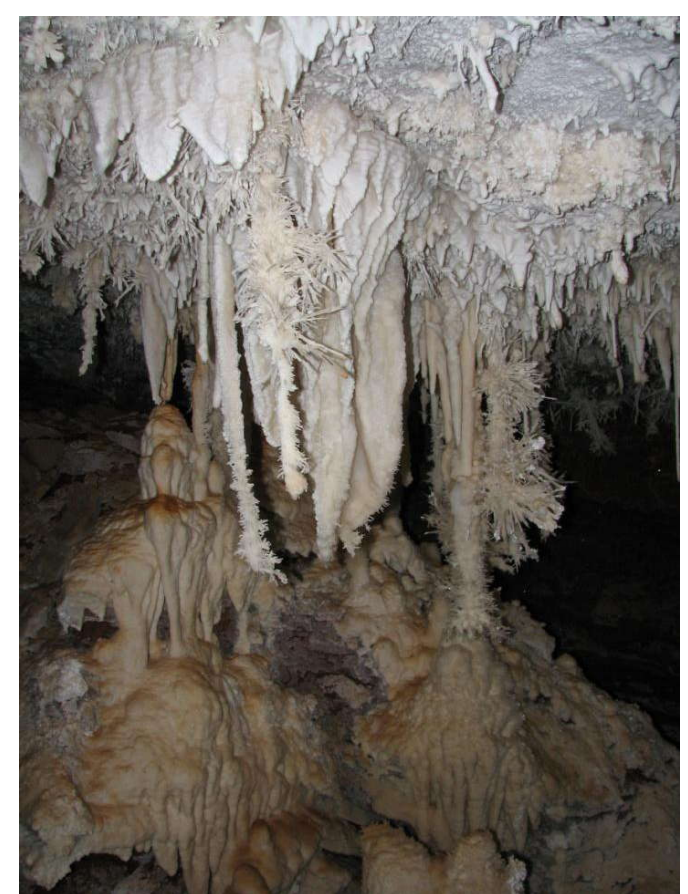

Autores: Juan Gil Montes y Área de Desarrollo Local de la Diputación Provincial de Cáceres. 
Figura 22. Corte geológico del macizo de Las Villuercas de Su roeste a Noreste.

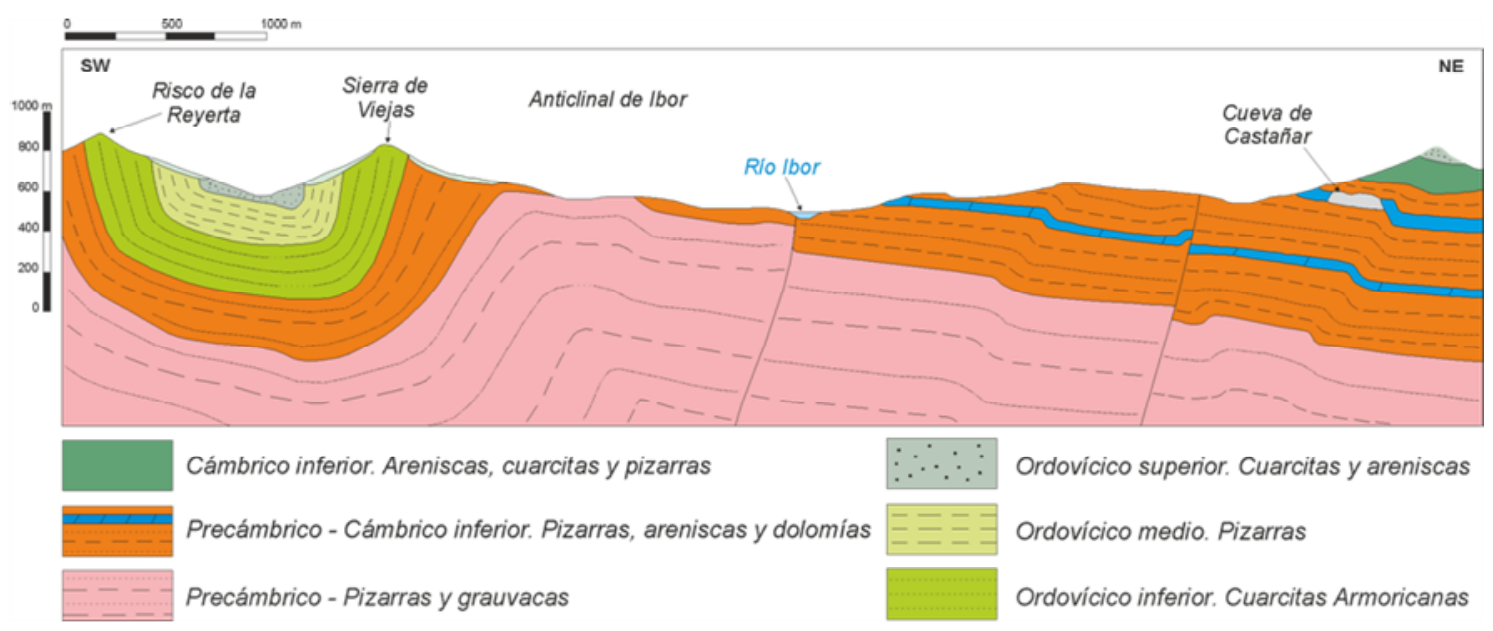

Elaboración propia a partir de Alonso Zarza et al. (2005).

Tabla 1. Geositios caracterizados por sus valores geológicos y turísticos.

\begin{tabular}{|c|c|c|c|}
\hline Nombre & & Valores geológicos & Valores turísticos \\
\hline $\begin{array}{l}\text { 1-Pico de } \\
\text { Villuerca" }\end{array}$ & La & $\begin{array}{l}\text { - Cumbre más elevada de Las Villuercas } \\
\text { (1601 m). } \\
\text { - Cuarcitas Armoricanas, Pliegues y } \\
\text { Pedreras. } \\
\text { - Características geomorfológicas: } \\
\text { Observación del Relieve Apalachense }\end{array}$ & $\begin{array}{l}\text { - Muy Alto } \\
\text { - Estética y paisaje: Muy Buenos } \\
\text { - Accesibilidad: Muy buena por } \\
\text { caminos y carretera } \\
\text { - Capacidad de carga: Alta }\end{array}$ \\
\hline $\begin{array}{l}\text { 2-Cerro de } \\
\text { Cristóbal }\end{array}$ & San & $\begin{array}{l}\text { - Batolito granítico y filones minerales, } \\
\text { poblado y castillo árabe } \\
\text { - Características geomorfológicas: } \\
\text { Observación del relieve de la penillanura } \\
\text { y las sierras } \\
\text { - Mineralogía y Petrología: Rocas } \\
\text { graníticas y filones de cuarzo, casiterita, } \\
\text { turmalinas, etc. }\end{array}$ & $\begin{array}{l}\text { - Alto } \\
\text { - Recursos de interpretación: } \\
\text { Museo y Centro de } \\
\text { Interpretación } \\
\text { - Estética y paisaje: Buenos } \\
\text { - Accesibilidad: Buena por caminos } \\
\text { - Capacidad de carga: Alta } \\
\text { - Publicaciones relacionadas: “La } \\
\text { Sierra de San Cristóbal de } \\
\text { Logrosán”, Sos Baynat, Vicente. }\end{array}$ \\
\hline
\end{tabular}




\begin{tabular}{|c|c|c|}
\hline $\begin{array}{l}\text { 3-Mina de } \\
\text { fosfatos del Filón } \\
\text { "La Costanaza" }\end{array}$ & $\begin{array}{l}\text { - Filón de fosforita y apatito en rocas } \\
\text { metamórficas } \\
\text { - Rocas precámbricas y aureola de } \\
\text { metamorfismo } \\
\text { - Mineralogía y Petrología: Cuarzo, } \\
\text { fosforita, fluorita, fluorapatito, pizarras } \\
\text { y grauvacas }\end{array}$ & $\begin{array}{l}\text { - Alto, pozos y galerías mineras en } \\
\text { fase de acondicionamiento } \\
\text { - Recursos de interpretación: } \\
\text { Museo y Centro de } \\
\text { Interpretación } \\
\text { - Accesibilidad: Buena por } \\
\text { carreteras } \\
\text { - Capacidad de carga: Grupos } \\
\text { reducidos } \\
\text { - Gestión y mejoras para su } \\
\text { conservación y uso: Realizadas } \\
\text { por la Junta de Extremadura y el } \\
\text { Ayuntamiento de Logrosán. }\end{array}$ \\
\hline $\begin{array}{l}\text { 4-Rañas de las } \\
\text { Mesas de } \\
\text { Cañamero y Alía }\end{array}$ & $\begin{array}{l}\text { - Depósitos sedimentarios del Plioceno } \\
\text { - Características } \\
\text { Conglomerados de cantos rodados y } \\
\text { matriz arcillosa } \\
\text { - Características } \\
\text { Mesetas separadas por profundos } \\
\text { barrancos } \\
\text { - Mineralogía y Petrología: Cuarzos y } \\
\text { cuarcitas. }\end{array}$ & $\begin{array}{l}\text { - Alto } \\
\text { - Estética y paisaje. Buenos } \\
\text { - Accesibilidad: Muy buena, por } \\
\text { carreteras y caminos } \\
\text { - Capacidad de carga: Alta } \\
\text { - Publicaciones relacionadas: } \\
\text { Numerosas }\end{array}$ \\
\hline $\begin{array}{l}\text { 5-Estrecho de la } \\
\text { "Peña Amarilla" }\end{array}$ & $\begin{array}{l}\text { - Discordancia geológica: } \\
\text { Cámbrico/Ordovícico, yacimiento de } \\
\text { icnofósiles (crucianas) en las cuarcitas } \\
\text { del Ordovícico } \\
\text { - Características geológicas: Crestones de } \\
\text { cuarcitas fallados, discordancia, } \\
\text { desfiladero y yacimiento fósil. } \\
\text { - Características geomorfológicas: } \\
\text { Fractura transversal que origina un } \\
\text { encajamiento fluvial con profundo } \\
\text { desfiladero del río Jarigüela. } \\
\text { - Mineralogía y Petrología: Cuarcitas } \\
\text { armoricanas, diabasas y pizarras } \\
\text { - Paleontología: Crucianas, Icnofósiles del } \\
\text { Ordovícico }\end{array}$ & $\begin{array}{l}\text { - Alto } \\
\text { - Estética y paisaje: Muy buenos } \\
\text { - Accesibilidad: Muy buena, por } \\
\text { carretera. } \\
\text { - Capacidad de carga: Alta } \\
\text { - Publicaciones relacionadas: } \\
\text { Geodiversidad y Lugares de } \\
\text { interés geológico de } \\
\text { Extremadura }\end{array}$ \\
\hline $\begin{array}{l}\text { 6-Nacimiento del } \\
\text { Río Almonte }\end{array}$ & $\begin{array}{l}\text { - Enorme pedrera de edad cuaternaria } \\
\text { - Características geológicas: Bloques de } \\
\text { cuarcitas permeables } \\
\text { - Características geomorfológicas: } \\
\text { Depósitos de ladera muy inestables } \\
\text { - Mineralogía y Petrología: Cuarcitas } \\
\text { armoricanas y cuarzos }\end{array}$ & $\begin{array}{l}\text { - Alto } \\
\text { - Estética y paisaje: Nacimiento de } \\
\text { un río debajo de la Pedrera } \\
\text { - Accesibilidad: Buena, por un } \\
\text { camino hormigonado } \\
\text { - Capacidad de carga: Grupos } \\
\text { numerosos }\end{array}$ \\
\hline
\end{tabular}




\begin{tabular}{|c|c|c|}
\hline $\begin{array}{l}\text { 7-Desfiladero del } \\
\text { río Ruecas }\end{array}$ & $\begin{array}{l}\text { - Profundo valle en cuarcitas armoricanas } \\
\text { y pizarras ordovícicas. } \\
\text { - Características geológicas: La erosión } \\
\text { fluvial en materiales de distinta dureza. } \\
\text { - Características geomorfológicas: } \\
\text { Desfiladero } \\
\text { - Mineralogía y Petrología: Cuarcitas y } \\
\text { pizarras } \\
\text { - Paleontología: Yacimientos de Crucianas }\end{array}$ & $\begin{array}{l}\text { - } \text { Alto } \\
\text { - Desfiladero. Yacimientos de } \\
\text { crucianas y pinturas rupestres } \\
\text { - Estética y paisaje: Pinturas } \\
\text { rupestres, Centro de } \\
\text { Interpretación de la Fauna } \\
\text { - Accesibilidad: Buena por caminos } \\
\text { - Capacidad de carga: Grupos } \\
\text { numerosos. } \\
\text { - Publicaciones relacionadas: } \\
\text { Estudios de las pinturas } \\
\text { rupestres }\end{array}$ \\
\hline $\begin{array}{l}\text { 8-Valle } \\
\text { Guadalupejo } \\
\text { Barranco } \\
\text { Valdegracia }\end{array}$ & $\begin{array}{l}\text { - Valle del Guadalupejo en pizarras } \\
\text { precámbricas. } \\
\text { - Características geológicas: La erosión } \\
\text { fluvial en materiales de distinta } \\
\text { naturaleza. } \\
\text { - Características geomorfológicas: Relieve } \\
\text { apalachense, pedreras, pico La Villuerca } \\
\text { - Mineralogía y Petrología: Cuarcitas, } \\
\text { pizarras y calizas }\end{array}$ & $\begin{array}{l}\text { - Alto. } \\
\text { - Estética y paisaje: Muy buenos } \\
\text { - Accesibilidad: Buena por } \\
\text { carretera } \\
\text { - Capacidad de carga: Grupos } \\
\text { numerosos }\end{array}$ \\
\hline $\begin{array}{l}\text { 9-Portilla } \\
\text { Almonte } \\
\text { (Apreturas } \\
\text { Almonte) }\end{array}$ & $\begin{array}{l}\text { - Muy alto, Era Paleozoica } \\
\text { - Características geológicas: Estructuras } \\
\text { de plegamiento } \\
\text { - Características geomorfológicas: Pliegue } \\
\text { en rodilla }\end{array}$ & $\begin{array}{l}\text { - } \text { Muy alto } \\
\text { - Estética y paisaje: Alto, } \\
\text { deformación rocosa por } \\
\text { plegamiento. } \\
\text { - Accesibilidad: buena, por } \\
\text { carretera (últimos metros a pie) } \\
\text { - Capacidad de carga: media } \\
\text { - Publicaciones relacionadas: } \\
\text { Geodiversidad y Lugares de } \\
\text { interés geológico de } \\
\text { Extremadura. }\end{array}$ \\
\hline $\begin{array}{lr}\text { 10-Sinclinal de } \\
\text { Santa Lucía (Peña } \\
\text { Buitrera } \\
\text { Castillo } \\
\text { Cabañas) }\end{array}$ & $\begin{array}{l}\text { - Muy alto, Era Paleozoica } \\
\text { - Características geológicas: } \\
\text { megaestructura-pliegue sinclinal } \\
\text { - Características geomorfológicas: } \\
\text { sinclinal-valle fluvial: relieve conforme } \\
\text { - Paleontología: Cruzianas, Scolitus }\end{array}$ & $\begin{array}{l}\text { - Muy alto } \\
\text { - Estética y paisaje: alto, valle } \\
\text { fluvial entre alineaciones } \\
\text { cuarcíticas (con buzamiento } \\
\text { convergente) } \\
\text { - Accesibilidad: muy buena, por } \\
\text { carretera } \\
\text { - Capacidad de carga: alta } \\
\text { - Publicaciones relacionadas: } \\
\text { Geodiversidad y Lugares de } \\
\text { interés geológico de } \\
\text { Extremadura }\end{array}$ \\
\hline
\end{tabular}




\begin{tabular}{|c|c|c|}
\hline $\begin{array}{l}\text { 11-Anticlinal } \\
\text { río Almonte }\end{array}$ & $\begin{array}{l}\text { - Alto, Era Paleozoica } \\
\text { - Características geológicas: } \\
\text { megaestructura-pliegue anticlinal } \\
\text { - Características geomorfológicas: } \\
\text { anticlinal-valle fluvial: relieve } \\
\text { disconforme. }\end{array}$ & $\begin{array}{l}\text { - Alto } \\
\text { - Estética y paisaje: alto, valle } \\
\text { fluvial entre alineaciones } \\
\text { cuarcíticas (con buzamiento } \\
\text { divergente) } \\
\text { - Accesibilidad: muy buena, por } \\
\text { carretera } \\
\text { - Capacidad de carga: alta } \\
\text { - Publicaciones relacionadas: } \\
\text { Geodiversidad y Lugares de } \\
\text { interés geológico de } \\
\text { Extremadura }\end{array}$ \\
\hline $\begin{array}{l}\text { 12-Anticlinal del } \\
\text { río Ibor- } \\
\text { Guadalupe }\end{array}$ & $\begin{array}{l}\text { - Alto, formación geológica Alogrupo Ibor, } \\
\text { Era Paleozoica } \\
\text { - Características geológicas: } \\
\text { megaestructura-pliegue anticlinal } \\
\text { - Características geomorfológicas: } \\
\text { anticlinal-valle fluvial: relieve } \\
\text { disconforme }\end{array}$ & $\begin{array}{l}\text { - Alto } \\
\text { - Estética y paisaje: alto, valle } \\
\text { fluvial entre alineaciones } \\
\text { cuarcíticas (con buzamiento } \\
\text { divergente) } \\
\text { - Accesibilidad: muy buena, por } \\
\text { carretera } \\
\text { - Capacidad de carga: alta } \\
\text { - Publicaciones relacionadas: } \\
\text { Geodiversidad y Lugares de } \\
\text { interés geológico de } \\
\text { Extremadura }\end{array}$ \\
\hline $\begin{array}{l}\text { 13-Anticlinal } \\
\text { Valdelacasa }\end{array}$ & $\begin{array}{l}\text { - Alto, formación geológica Valcasa, Era } \\
\text { Paleozoica } \\
\text { - Características geológicas: anticlinal } \\
\text { arrasado (superficie de penillanura) } \\
\text { - Características geomorfológicas: relieve } \\
\text { de erosión (penillanura) }\end{array}$ & $\begin{array}{l}\text { - Alto } \\
\text { - Estética y paisaje: media, relieve } \\
\text { de penillanura } \\
\text { - Accesibilidad: muy buena, por } \\
\text { carretera } \\
\text { - Capacidad de carga: alta } \\
\text { - Publicaciones relacionadas: } \\
\text { Geodiversidad y Lugares de } \\
\text { interés geológico de } \\
\text { Extremadura }\end{array}$ \\
\hline $\begin{array}{l}\text { 14-Sinclinal } \\
\text { río Viejas }\end{array}$ & $\begin{array}{l}\text { - Valor geológico y cronoestratigrafía: } \\
\text { alto, Era Paleozoica } \\
\text { - Características } \\
\text { megaestructura-pliegue sinclinal } \\
\text { - Características geológicas: } \\
\text { sinclinal-valle fluvial: relieve conforme } \\
\text { - Paleontología: } \\
\text { paleontológicos yacimientos } \\
\text { spyriféridos, trilobites) }\end{array}$ & $\begin{array}{l}\text { - Valor geoturístico: alto } \\
\text { - Estética y paisaje: alto, valle } \\
\text { fluvial entre alineaciones } \\
\text { cuarcíticas (con buzamiento } \\
\text { convergente) } \\
\text { - Accesibilidad: buena, por } \\
\text { carretera } \\
\text { - Capacidad de carga: media-alta } \\
\text { - Publicaciones relacionadas: } \\
\text { Geodiversidad y Lugares de } \\
\text { interés geológico de } \\
\text { Extremadura }\end{array}$ \\
\hline
\end{tabular}




\begin{tabular}{|c|c|c|}
\hline $\begin{array}{l}\text { 15-Monumento } \\
\text { Natural "Cueva } \\
\text { de Castañar" }\end{array}$ & $\begin{array}{l}\text { - Muy alto, Era Paleozoica } \\
\text { - Características geológicas: carstificación } \\
\text { de rocas carbonatadas con } \\
\text { espeleotemas de aragonito } \\
\text { - Características geomorfológicas: } \\
\text { carstificación subterránea } \\
\text { - Mineralogía y Petrología: aragonito, } \\
\text { rocas carbonatadas, pizarras }\end{array}$ & $\begin{array}{l}\text { - Muy alto } \\
\text { - Estética y paisaje: muy alto, } \\
\text { carstificación subterránea } \\
\text { - Accesibilidad: mala, descenso } \\
\text { vertical dificultoso y recorrido } \\
\text { horizontal estrecho y sinuoso } \\
\text { - Capacidad de carga: baja-muy } \\
\text { baja } \\
\text { - Publicaciones relacionadas: } \\
\text { Geodiversidad y Lugares de } \\
\text { interés geológico de } \\
\text { Extremadura }\end{array}$ \\
\hline
\end{tabular}

Fuente: Inventario de Geositios del Geoparque Villuercas-Ibores-Jara, realizado por expertos de la AGEx y de la UEX y por técnicos y expertos en Turismo de la Diputación Provincial de Cáceres durante el período de candidatura a la EGN. Información disponible on-line en la página web: http://geoparquevilluercas.es/oadl/documents/4-AD.pdf [consultado: 26/01/2013].

\section{CONCLUSIONES}

En la comarca de Villuercas-Ibores-Jara, pese a sus pequeñas dimensiones, es posible observar un amplio conjunto de recursos naturales diferentes. La complicada historia geológica que ha sufrido este territorio, junto a las características climáticas pasadas y actuales, han dado como resultado un conjunto de formas de modelado que hacen que este espacio geográfico cuente con una gran variedad de paisajes de un enorme atractivo. Pero son la geología y la geomorfología las que marcan de manera rotunda la identidad de la comarca, conocida en el mundo científico por la singularidad de su relieve "apalachense". Además, es muy rica en elementos de interés geológico, como las rañas, la sucesión continuada de sierras y valles paralelos que en sus altas cumbres, umbrías, solanas, vegas, etc. albergan una biodiversidad muy rica y, a veces, exclusiva, ejemplificada claramente en las loreras y en las buitreras.

Desde hace varios años se están llevando a cabo diversas iniciativas para el desarrollo del turismo rural y de naturaleza, aprovechando el tradicional movimiento de turistas que afluyen hacia Guadalupe, como principal foco de atracción para un turismo que, cada vez más, está demandando determinados servicios relacionados con el disfrute de la naturaleza y no sólo de carácter religioso-cultural. El perfil del demandante de este tipo de turismo es cada más exigente, opera on-line y necesita más información, de ahí que las instituciones locales y regionales estén llevando a cabo acciones contempladas en el Plan de Dinamización del Producto Turístico, impulsando servicios y equipamientos, como centros de interpretación y el diseño de paquetes turísticos cuya oferta está determinada por los recursos naturales de la zona.

Este incipiente turismo, demandado generalmente por grupos pequeños de familiares y amigos aficionados a la naturaleza de tipo generalista, así como otros tipos de turistas más especializados e interesados principalmente en la observación de aves o en la visita de la Cueva de Castañar de Ibor, puede ser complementado con las 
actividades dirigidas al geoturismo. Mediante la reciente declaración de geoparque, se estima que aumente la oferta turística de la zona y que se impulse el desarrollo socioeconómico bajo criterios de calidad y sostenibilidad. Además, se presupone que no ocasionará ningún conflicto con la población local dedicada a otros menesteres, ya que la declaración de un espacio protegido por la figura de geoparque no supone ninguna limitación en el uso de los espacios, al contrario de lo que ocurre en figuras como parque nacional, parque o reserva natural, entre otras.

\section{AGRADECIMIENTOS}

Este trabajo habría sido imposible realizarlo sin la inestimable colaboración de Juan Gil Montes (http://jugimo.blogspot.com/), quien lleva toda su vida dedicado al estudio de la geología y arqueología de la zona. Agradecer también a las entidades que conforman el comité de redacción de la candidatura para la inclusión en la Red de Geoparques Europeos, entre las que destaca el Área de Desarrollo Local y Formación de la Diputación Provincial de Cáceres. El tercer autor agradece expresamente al Gobierno de Extremadura y al Fondo Social Europeo el disfrute de una beca predoctoral FPI (expediente PRE07009).

\section{REFERENCIAS BIBLIOGRÁFICAS}

ALONSO ZARZA, A.M., GIL PEÑA, I., MARTínEZ FLORES, E., MUÑOZ BARCO, P. (2005). La cueva de Castañar. In: "Patrimonio Geológico de Extremadura: geodiversidad y lugares de interés geológico", P. Muñoz Barco \& E., Martínez Flores, eds., Dirección General de Medio Ambiente, Consejería de Agricultura y Medio Ambiente. Junta de Extremadura, Mérida, 99-111.

BRILHA, J. (2005). Património geológico e geoconservação: A conservação da natureza na sua vertente geológica. Viseu, Portugal. Palimage Editores.

CHIAS, J. (2005). El negocio de la felicidad: desarrollo y marketing turístico de países, regiones, ciudades y lugares. Madrid, Prentice Hall.

DIRECCIÓN GENERAL DE TURISMO DE EXTREMADURA (2010). Plan Estratégico de Turismo para Extremadura 2010-2015. Mérida, Junta de Extremadura.

DOMínGUEZ, L. \& RODRíGUEZ, A. (2007). "Potencial geológico-geomorfológico de la región de Moa para la propuesta del modelo de gestión de sitios de interés patrimonial". Minería y Geología 23: 1-22.

FARSANI, N.T., COELHO, C. \& COSTA, C. (2011). "Geotourism and Geoparks as novel strategies for socio-economic development in rural areas". International Journal of Tourism Research 13: 68-81.

FORTUNATO, N. (2005). "El territorio y sus representaciones como recurso turístico. Valores fundacionales del concepto de parque nacional". Estudios y Perspectivas en Turismo 14: 314-348.

GÓMEZ, D. (1985). La penillanura extremeña: estudio geomorfológico. Cáceres. Universidad de Extremadura. 
JUNTA DE EXTREMADURA (2011). Estrategia para el Desarrollo Sostenible de Extremadura. Mérida, Junta de Extremadura.

LÓPEZ OLIVARES, D. (1998).: La ordenación y planificación integrada de los recursos territoriales turísticos. Castelló de la Plana, Universitat Jaume I.

MORA, J., NOGALES, J. M., GUTIÉRREZ, J. A. \& CORTÉS, T. (2003). "Aplicación de técnicas SIG en la planificación del transporte por carretera en Extremadura (España).". Finisterra 75: 67-83.

PULIDO, M., LAGAR, D. \& GARCÍA, R. (2011). El geoturismo como estrategia de desarrollo en áreas rurales deprimidas: propuesta de geoparque Villuercas, Ibores, Jara (Extremadura).. Boletín de la Asociación de Geógrafos Españoles 56: 485-498.

PULIDO, M., LAGAR, D. \& GARCÍA, R. (In Review). "Geosites Inventory in the Geopark Villuercas-Ibores-Jara (Extremadura, Spain).: A new way of promoting the geoheritage conservation". Geoheritage.

ROCA FERNÁNDEZ-CASTANYS, M.L. (2004). El aprovechamiento turístico de los espacios naturales protegidos (Régimen jurídico).. Sevilla, Consejería de Turismo, Comercio y Deporte, Junta de Andalucía.

ROMERO, A. \& BELMONTE, F. (2002). "Los paisajes geomorfológicos de la Región de Murcia como recurso turístico". Cuadernos de Turismo 9: 103-122.

UNESCO (1999). UNESCO Geoparks Programme. A new initiative to promote a global network of Geoparks safeguarding and devoloping selected areas having significant geological features. París, Francia. Proceedings of $156^{\text {th }}$ Session of UNESCO Executive Board, $156 \mathrm{Ex} / 11$.

VERA, J.F.; LÓPEZ PALOMEQUE, F.; MARCHENA, M.: ANTON CLAVÉ, S. (2011). Análisis Territorial del Turismo y Planificación de Destinos Turísticos. València, Editorial Tirant Lo Blanch.

VILLALOBOS, M. (2000). Estrategias en la protección del patrimonio geológico andaluz. Monográficos Medio Ambiente 37. Consejería del Medio Ambiente, Junta de Andalucía.

ZOUROS, N. (2004). "The European Geoparks Network. Geological heritage protection and local development". Episodes 27: 165-171.

ZOUROS, N. \& MARTINI, G. (2003). "Introduction to the European Geoparks Network". En: Proceedings of the 2nd European Geoparks Network Meeting. Lesvos, Grecia, Natural History Museum of the Lesvos Petrified Forest: 17-21. 